\title{
Research Paper: \\ The Nephroprotective Effect of Clove Oil (Oleum Caryophylli) Against Levofloxacin Toxicity in Rats
}

\author{
Anitsah Fiqardina1 $^{1}$ (D), Yulia Yusrini Djabir ${ }^{2 *}$ (D), Arif Santoso ${ }^{3}$ (D), Syafira Nurul Salsabil ${ }^{1}$ (D) Ismail Ismail $^{4}$ (D)
}

1. Clinical Pharmacy Laboratory, Faculty of Pharmacy, Hasanuddin University, Makassar, Indonesia

2. Department of Pharmacy, Faculty of Pharmacy, Hasanuddin University, Makassar, Indonesia.

3. Department of Pulmonology, Faculty of Medicine, Hasanuddin University, Makassar, Indonesia.

4. Department of Pharmaceutical Science and Technology, Faculty of Pharmacy, Hasanuddin University, Makassar, Indonesia.

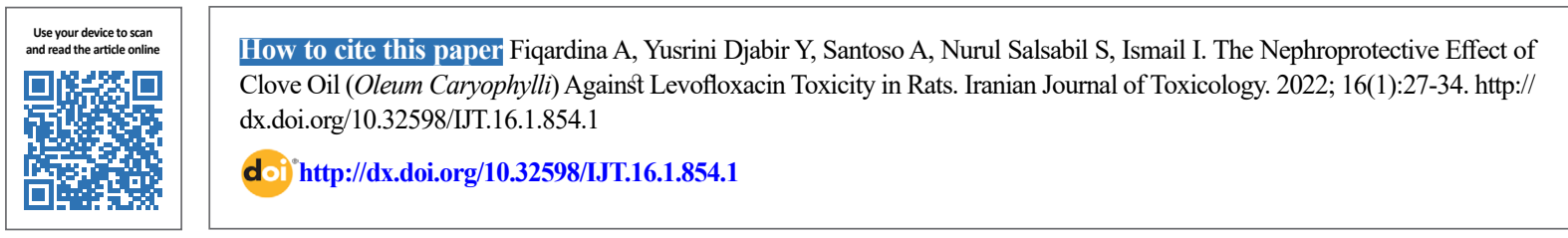

\section{(i) (3)}

Article info:

Received: 20 Jul 2021

Accepted: 02 Nov 2021

Online Published: 01 Jan 2022

\footnotetext{
* Corresponding author:

Yulia Yusrini Djabir, PhD.

Address: Department of Pharmacy,

Faculty of Pharmacy, Hasanuddin

University, Makassar, Indonesia.

E-mail:yulia.yusrini@unhas.ac.id
}

\section{ABSTRACT}

Background: Levofloxacin is a fluoroquinolone antibiotic that has broad-spectrum antimicrobial activity, but it may induce kidney dysfunction. Clove oil (Oleum caryophylli) has antioxidant properties that may alleviate levofloxacin toxicity. This study aimed to examine the protective effect of clove oil on levofloxacin-induced nephrotoxicity in rat animal models.

Methods: A total of 24 male rats were divided into 6 groups. One group did not receive levofloxacin to serve as the control. The treatment groups received a single daily administration of levofloxacin $(93 \mathrm{mg} / \mathrm{kg})$ with either placebo or clove oil $(10 \mathrm{mg} / \mathrm{kg}, 25 \mathrm{mg} / \mathrm{kg}$, or $50 \mathrm{mg} /$ $\mathrm{kg}$ per body weight) pre-treatment. Another group received Curcuma extract pre-treatment as a comparison. Blood samples were withdrawn after 28 days of treatment to measure serum biomarkers (urea and creatinine), and the kidneys were removed to measure renal Malondialdehyde (MDA) and histopathological analysis.

Results: The results showed that clove oil pre-treatment at a dose of $10 \mathrm{mg} / \mathrm{kg}$ was able to reduce renal MDA and serum biomarker levels $(\mathrm{P}<0.05)$. The effect was similar to that found in Curcuma-treated rats. In addition, clove oil $(10 \mathrm{mg} / \mathrm{kg})$ was also found to ameliorate renal histopathological damage due to levofloxacin.

Conclusion: Based on biomarker and histopathological analysis, clove oil pre-treatment in rats provides a nephroprotective effect against levofloxacin toxicity.

Keywords: Clove oil, Levofloxacin, Nephrotoxicity, Oleum caryophylli, Syzygium aromaticum

\section{Introduction}

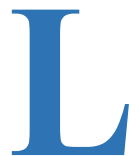

evofloxacin is a fluoroquinolone antibiotic with broad-spectrum antibacterial activity. Levofloxacin acts by inhibiting topoisomerase II or Deoxyribonucleate (DNA) gyrase enzymes in bacteria. This activity instigates a disruption in DNA replication, and ultimately, leads to the bacterial death [1]. Since
DNA gyrase enzyme, also present in Mycobacterium tuberculosis, levofloxacin has been included in the management of tuberculosis, as a second-line treatment [2]. For Multi-Drug-Resistant (MDR) patients with tuberculosis, the fluoroquinolone-based regimen is commonly prescribed for nine to eleven months, on average [3].

Since the treatment of MDR TB requires long-term therapy, the use of fluoroquinolone can increase the risk 
of unwanted side effects [4]. The serious side effects of fluoroquinolones include liver dysfunction, drug-induced hepatitis, and cholestasis [5]. In addition, fluoroquinolones may also cause kidney failure [6]. It has been reported that approximately $50 \%$ of MDR TB patients experience renal disorders, which may progress to endstage renal disease and mortality [7].

Employing natural resources is likely to be indispensable in efforts to minimize the risk of fluoroquinolones toxicity. Studies have shown that natural resources containing antioxidants are beneficial to reduce nephrotoxicity in animal models $[8,9]$. Clove essential oil (Oleum caryophylli) is one of the essential compounds that have been widely demonstrated to elicit antioxidant activities $[10,11]$. Depending on its origin, clove oil may comprise at least 65 chemical components, with eugenol being 75 $83 \%$ of the main constituent $[11,12]$. Eugenol in clove oil is established to possess free radical scavenging properties, which is more potent than standard antioxidants, such as alpha-tocopherol, and Butylated Hydroxyanisole and Hydroxytoluene (BHA \& BHT) formulations [13]. A preliminary study has shown that clove oil treatment could be beneficial to reduce the biomarker levels of liver and kidney damages at a dose of $10 \mathrm{mg} / \mathrm{kg}$ in rats induced by the toxic dose of isoniazid-rifampicin [14]. We assumed it would be clinically of significance to explore whether clove oil may also protect renal tissue from levofloxacin toxicity. Toward this putative goal, this study investigated the nephroprotective effect of clove oil on levofloxacin-induced kidney damage in a rat model.

\section{Materials and Methods}

Chemicals and drugs: The clove oil used in this study has been standardized and provided with a certificate of analysis (Happy Green ${ }^{\circledR}$, Indonesia). Levofloxacin generic tablets $(500 \mathrm{mg}$ ) were purchased from Kimia Farma (Makassar, Indonesia). Curcuma ${ }^{\circledR}$ FCT (Soho, Indonesia) was purchased from a local pharmacy, which each tablet contains $20 \mathrm{mg}$ of Curcuma xanthorrhiza rhizome extract. All diagnostic kits for renal biomarkers were purchased from Human Diagnostics Worldwide (Germany), while 1,1,3,3 Tetra-Methoxy-Propane (TMP) solution for Malondialdehyde (MDA) measurement was purchased from Sigma Aldrich (Singapore).

Animals: The experimental animals consisted of 24 male Wistar albino rats (Rattus norvegicus) with 200$250 \mathrm{~g}$ of body weight. Animals were procured from an animal breeding facility (Yogyakarta, Indonesia). All animals were adapted to laboratory conditions for 7 days prior to initiating the experiments. All experimental pro- tocols involving animals have been granted an institutional ethical clearance number of UH20050197 under Hasanuddin University.

Thin Layer Chromatography (TLC): The presence of eugenol in the clove oil sample was analyzed using Thin Layer Chromatography (TLC). The clove oil sample and the eugenol standard were compared using a silica gel GF 254 plate as the stationary phase and toluene: acetone (3:1) as the mobile phase. The stains were observed under $254 \mathrm{~nm}$ UV light and visualized with an anisaldehyde-sulfuric acid reagent. The presence of eugenol in the clove oil sample is indicated by the presence of a stain that has a similar Retention factor (Rf) value as the standard eugenol compound.

Preparation of clove oil: The multiple oral doses of clove oil that give No Observed Adverse Effect Level (NOAEL) in rats is $200 \mathrm{mg} / \mathrm{kg}$ [15]. Consequently, the dose given in this study should not be above the NOAEL. The doses chosen were $10 \mathrm{mg} / \mathrm{kg}, 25 \mathrm{mg} / \mathrm{kg}$, and $50 \mathrm{mg} / \mathrm{kg}$ body weight of rats, which was based on a pilot study [14]. Clove oil was diluted with corn oil to make a solution with a concentration of $0.1 \%, 0.25 \%$, $0.5 \% \mathrm{v} / \mathrm{v}$. The clove oil solution was orally administered at a volume of $1 \mathrm{ml} / 100 \mathrm{~g}$ in rats.

Preparation of levofloxacin suspension: The levofloxacin dose used in this study was converted from the highest therapeutic dose in humans $(15 \mathrm{mg} / \mathrm{kg})$. Based on a calculation of the conversion of human dose to animal dose by Nair and Jacob [16], the levofloxacin dose for rats is equal to $93 \mathrm{mg} / \mathrm{kg}$. The levofloxacin suspension was prepared by suspending levofloxacin powder in $1 \%$ sodium carboxymethyl cellulose and was orally administered at a volume of $1 \mathrm{ml} / 100 \mathrm{~g}$ in rats.

Preparation of Curcuma suspension: Curcuma xanthorrhiza extract is generally used as a hepatoprotective agent, but several studies have also shown the putative nephroprotective effect of Curcuma extract, and thereby, it was used as a comparison treatment in this study [17]. The animals received a $6.2 \mathrm{mg} / \mathrm{kg}$ daily dose of Curcuma extract based on the calculation of the dose conversion of experimental animals [16]

Experimental protocols: The rats were assigned into one of the six groups. A group that did not receive levofloxacin was assigned as the control. The treatment groups were pre-treated with either placebo (corn oil) or clove oil $(10 \mathrm{mg} / \mathrm{kg}, 25 \mathrm{mg} / \mathrm{kg}$, or $50 \mathrm{mg} / \mathrm{kg}$ ) before administration of levofloxacin suspension. Another group was pre-treated with Curcuma extract as a comparison (posi- 
tive control). The levofloxacin administration was carried out for 28 consecutive days, and the pre-treatments were given 2 hours before levofloxacin on a daily basis. At the end of the experiment, blood samples were withdrawn to measure the levels of renal function biomarkers. Twenty-four hours following blood withdrawal, the rats were euthanized by cervical dislocation and the kidneys were harvested. One kidney was fixed in $10 \%$ formalin for histopathological analysis, while the other kidney was frozen using liquid nitrogen for renal MDA assays [18].

Measurement of serum biomarkers: Blood was collected from the lateral vein of rats and stored in EDTA tubes ( $\mathrm{BD}^{\circledR}$ vacutainer) and centrifuged for 20 minutes at $3000 \mathrm{rpm}$. The measurement of renal biomarkers is performed as described in a previous study [8]. Serum biomarker analysis was performed using urea and creatinine liquicolor diagnostic kits according to the instructions. The absorbance was measured using a Humalyzer 3500 instrument (Human Diagnostics, Makassar, Indonesia).

Measurement of renal malondialdehyde levels: The MDA levels were measured using the Thiobarbituric Acid Reactive Substances (TBARS) method modified from Adnan et al. study [19]. A total of $400 \mathrm{mg}$ of kidney tissue were homogenized with $2 \mathrm{~mL}$ of phosphate buffer $(\mathrm{pH}$ 7.4). The mixture was centrifuged for 10 minutes at $3000 \mathrm{rpm}$. The supernatant $(0.5 \mathrm{~mL})$ was collected in a tube and added with $1 \mathrm{~mL}$ of $1 \%$ thiobarbituric acid and $1 \mathrm{ml}$ of $10 \%$ Trichloroacetic acid and heated using a water bath at $100 \mathrm{oC}$ for 20 minutes. The mixture was centrifuged for another 20 minutes at $3000 \mathrm{rpm}$ to remove precipitates. The absorbance was measured using a UV-Vis spectrophotometer at a wavelength of $531 \mathrm{~nm}$.

Histopathological examination: The kidneys specimens were excised into $0.5-1 \mathrm{~cm}$ thick, embedded, and processed in a tissue processor. The specimens were removed and stored in molds and filled with paraffin. The paraffin blocks were sliced (3-4 $\mu \mathrm{m})$ using a microtome. The tissues were stained using hematoxylin and eosin. Microscopic examination of the renal tissues was carried out using a light microscope (Olympus ${ }^{\circledR}$ ) with a magnification of $100 \times$ and $400 \times$.

Statistical analyses: The normal distribution of the data was analyzed using Kolmogorov-Smirnov analysis. Normally distributed data were analyzed with oneway ANOVA followed by a Tukey's HSD post-hoc test. If the data distribution is not normal, a Kruskal Wallis and Mann-Whitney test were employed. Significant differences were confirmed when the P-value $<0.05$.

\section{Results}

Thin layer chromatographic analysis of clove oil: Clove oil is known to contain high eugenol compounds. In this study, the clove oil sample was qualitatively analyzed, using Thin Layer Chromatographic (TLC) method and the result confirmed the presence of eugenol compound in the sample as reflected in Figure 1.

Renal malondialdehyde levels: Figure 2 illustrates the amount of renal MDA levels of each group before and after receiving the treatment. It is evident that the group of rats that received levofloxacin and placebo $(\mathrm{L}+$ placebo) for 28 days had the highest level of renal MDA. This indicated that levofloxacin triggered oxidative damage in the rats' kidneys which increased the lipid peroxidation activity as reflected by the high MDA level in the tissue. As seen in Figure 2, the oral administration of clove oil significantly reduced the renal MDA levels compared to the group that received the placebo treatment. At 10-25 $\mathrm{mg} / \mathrm{kg}$ doses, the clove oil treatment inhibited the rise in MDA levels as effectively as the Curcuma treatment.

Renal serum biomarkers: The results of the kidney function test, are as presented in Figure 3, demonstrate that the serum urea level markedly increased after administering levofloxacin for 28 days. Administration of clove oil 10, 25, and $50 \mathrm{mg} / \mathrm{kg}$ before levofloxacin treatment significantly inhibited the rise in serum urea levels $(\mathrm{P}<0.05)$. Even at the lowest dose of $10 \mathrm{mg} / \mathrm{kg}$, the protective effect of clove oil against urea level elevation was seen to be equivalent to that of Curcuma,

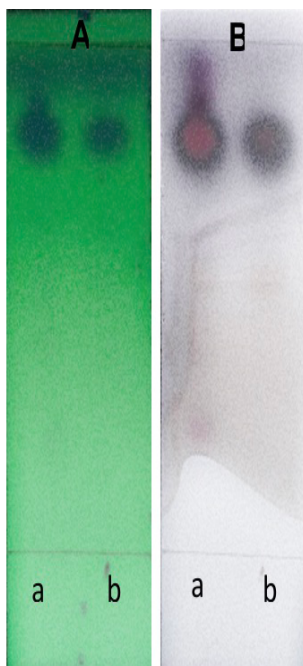

Figure 1. Results of thin-layer chromatography

Of clove (a) and standard eugenol (b) oil samples at $245 \mathrm{~nm}$ UV light (A) and after spraying of anisaldehyde-sulfuric acid reagent (B). 


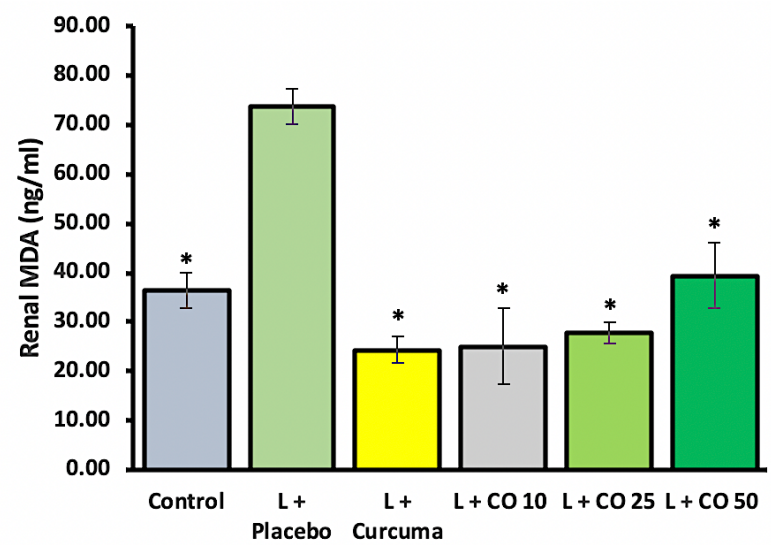

Figure 2. Renal malondialdehyde levels of rats after administration of levofloxacin and clove oil

L: Levofloxacin; CO: Clove Oil; " ${ }^{* *}<<0.01$ versus control; ${ }^{\# \# ~} \mathrm{P}<0.01$ versus $\mathrm{L}+$ placebo.

which was statistically very significant compared to that of the placebo group $(\mathrm{P}<0.01)$. The serum creatinine of the treatment groups also significantly increased after 28 days of levofloxacin administration. The creatinine levels decrease insignificantly after the administration of low $(10 \mathrm{mg} / \mathrm{kg})$ and intermediate $(25 \mathrm{mg} / \mathrm{kg})$ doses of clove oil. However, the high dose of clove oil $(50 \mathrm{mg} / \mathrm{kg})$ did not prevent the rise in the creatinine levels.

Histopathological examinations: Figure 4 shows the microscopic results of the renal tissue of rats in various treatment groups. The microscopic features of the kidney tissue samples in the normal control group were dominated by normal-looking cells. The glomeruli and tubules had normal appearance, devoid of inflammation and/or cellular degeneration (Figures 4 A-B). Meanwhile, in the levofloxacin plus placebo group, the rat renal tissues exhibited some degrees of fibrosis, necrosis, missing cellular nuclei, and the presence of hyaline cast (pink amorphous mass). Some renal tubules also showed signs of hydropic degeneration (Figures 4, C-D).

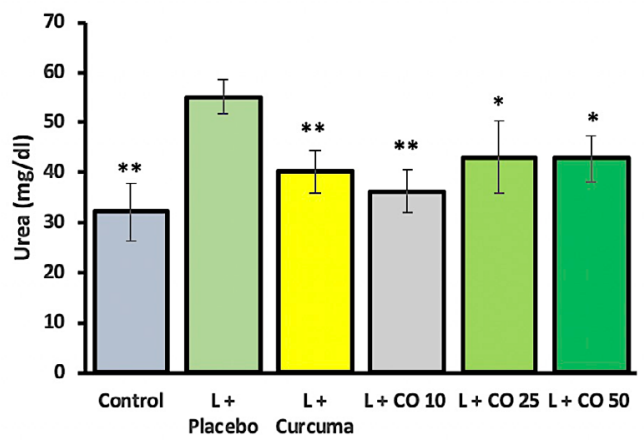

In the experimental group that received levofloxacin and clove oil $10 \mathrm{mg} / \mathrm{kg}$, some renal tissue samples exhibited mild hydropic degeneration and necrosis as evident by the presence of hyaline cast in the tubular lumens (Figure 4 E-F). Hydropic degeneration was characterized by the presence of large, pale tubular epithelial cells and clear vacuoles in the cytoplasm. Hydropic degeneration is an early stage of injury and it is considered reversible, which usually occurs due to the inability of the cells to maintain ion and fluid homeostasis. With levofloxacin and clove oil $(25 \mathrm{mg} /$ $\mathrm{kg}$ ) treatment, hemorrhagic areas were also observed in the renal tubules and congestion occurred in the vasculatures, but the glomerular structures did not appear altered (Figure $4 \mathrm{G}-\mathrm{H})$. Meanwhile, the renal tissue of rats that received levofloxacin plus clove oil at a dose of $50 \mathrm{mg} / \mathrm{kg}$ exhibited high degrees of renal damage, such as hyaline cast, hydropic degeneration, hemorrhage, and congestion (Figure 4 I-J). However, the damage was less evident than that in the placebo group, where nearly all of the rats had intense renal injury affecting most of the observed areas. Compared to the histopathology observed in the clove oil group, the rats in the Curcuma group exhibited mild renal damage, with

Figure 3. Serum urea and creatinine levels of rats after administration of levofloxacin and clove oil

L: Levofloxacin; CO: Clove Oil; ${ }^{*} \mathrm{P}<0.05$ and ${ }^{\text {** }} \mathrm{P}<0.01$ versus control; ${ }^{\# \# ~} \mathrm{P}<0.01$ versus $\mathrm{L}+$ placebo. 
hemorrhage and localized inflammatory cells in the examined renal areas (Figure $4 \mathrm{~K}-\mathrm{L}$ ).

\section{Discussion}

Long-term use of levofloxacin can cause nephrotoxicity causes oxidative stress. It has been known that glutathione synthesis declines rapidly following levofloxacin administration, leading to the body's inability to create a balance between the production of antioxidants and Reactive Oxygen species (ROS) [20]. The eugenol-like substance that exists in clove oil is a very potent antioxidant compound. Several studies have shown that eugenol can decrease the production of ROS and regulate the antioxidant balance [21-23]. This antioxidant effect is assumed to be capable of protecting against nephrotoxicity, e.g. due to the use of levofloxacin.

Our study results demonstrated that the renal MDA levels of rats treated with clove oil were significantly reduced after they received levofloxacin at a high dose for 28 days. The blood MDA level is an indicator of lipid peroxidation activity; therefore, its reduction suggests the reduced lipid peroxidation in rats treated with clove oil. The mechanism by which eugenol compounds inhibit lipid peroxidation may be in two stages. First, eugenol reduces the production of ROS by inhibiting the formation of oxygen singlets. Second, eugenol is metabolized into dimers and other associated compounds (e.g., diegenol), which further inhibits free radical chain reactions [24].

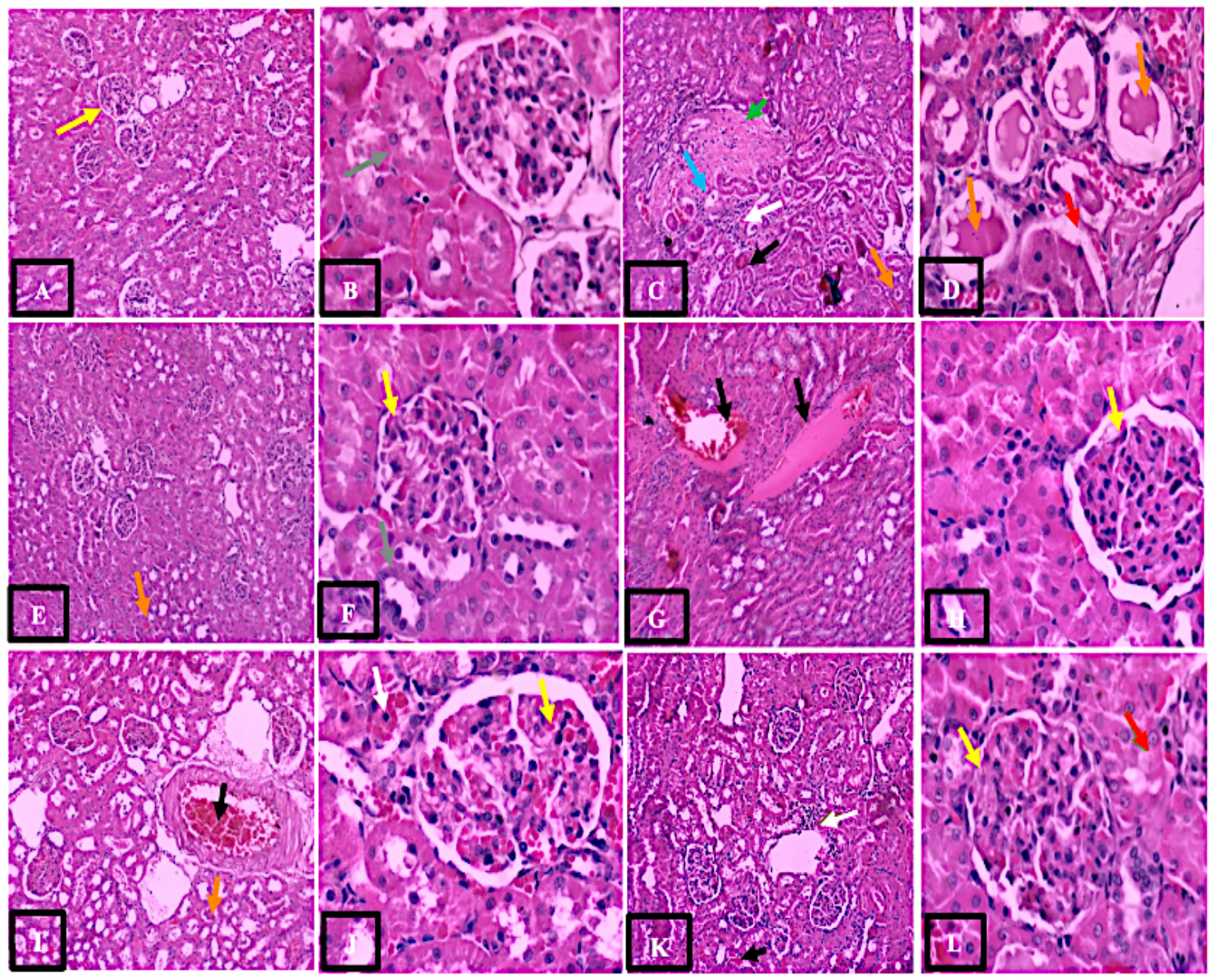

Figure 4. Histological microscopic images of the kidney of rats

In the control group (A, B) and those treated with levofloxacin and placebo (C, D); clove oil $10 \mathrm{mg} / \mathrm{kg}(\mathrm{E}, \mathrm{F})$, clove oil $25 \mathrm{mg} / \mathrm{kg}(\mathrm{G}, \mathrm{H})$, clove oil $50 \mathrm{mg} / \mathrm{kg}(\mathrm{I}, \mathrm{J})$, and curcuma extract $(\mathrm{K}, \mathrm{L})$.

Normal glomeruli (yellow arrows) and tubules (gray arrows). Fibrosis (green arrows), hyaline cast (orange arrows), inflammatory areas (white arrows), tubular degeneration (blue arrows), hemorrhage and congestion (black arrows), and hydropic degeneration (red arrows). Photomicrographs were taken at magnifications of 100x (A, C, E, G, I, K) and 400x (B, D, F, H, J, L), respectively. 
In addition to the renal MDA, we also measured the rats' renal function through serum urea and creatinine analysis, which are the widely used serum biomarkers of renal function. The increases in serum urea and creatinine levels indicate acute or chronic renal dysfunction [25]. In this study, the administration of clove oil (10 $\mathrm{mg} / \mathrm{kg}$ ) significantly reduced the elevation of serum urea caused an insignificant decrease in the creatinine level. This occurred partly due to a high standard deviation in the creatinine levels both in groups that received placebo and clove oil. For instance, several animals in the placebo group did not exhibit a marked elevation of creatinine level. It has been argued that a significant increase in creatinine level will only occur when the kidneys have lost at least $50 \%$ of their cellular function [26]. In a previous study, it was found that the process to induce renal toxicity was slower than hepatotoxicity in rats [27]. Therefore, it is important to provide a histopathological examination to support the biomarker results, thereby confirming the renal injury in rats.

Upon histopathological analysis, it was found that the damage to the renal tissue occurred most predominantly in the placebo group. The toxic metabolites of Levofloxacin are thought to stimulate renal oxidative stress since it facilitates the ROS formation [20]. The renal damage in the placebo-treated rats was more pronounced in the tubular areas compared to the glomeruli. Other features of renal injury in the placebo group were inflammatory cells infiltration and fibrosis. Tissue fibrosis often occurs when severe injury is accompanied by parenchymal and stromal damages to the tissue, replacing the parenchymal cells with connective tissue cells during recovery [28].

In this study, the clove oil treatment protected both the renal function and structures, especially at a $10 \mathrm{mg} / \mathrm{kg}$ dose. The protective effect was comparable to that of Curcuma extract treatment. In clinical settings, Curcuma extract is mostly prescribed as a hepaprotective agent. However, in this study, Curcuma extract was also shown to protect the histopathological structure of the kidney and maintained the renal MDA and serum urea at near-normal levels.

The renal protection of clove oil is thought to be stimulated by eugenol and other antioxidant compounds contained in it. These constituents reduce ROS production and lead to an amelioration of levofloxacin nephrotoxicity in rats, thereby, preventing the acute tubular necrosis [29]. In addition, eugenol may reinforce the body's endogenous antioxidants that are diminished due to levofloxacin administration [30]. It is interesting that the lowest clove oil dose $(10 \mathrm{mg} / \mathrm{kg})$ seemed to provide more protection against renal injury than the highest dose $(50 \mathrm{mg} / \mathrm{kg})$. Further research is required to inves- tigate the reason why the high doses of clove oil failed to protect against the Levofloxacin toxicity. This might have occurred partly due to eugenol cytotoxicity at its high concentrations [22]. A thorough toxicological study of clove bud extract has been conducted by Vijayasteltar, et al. in 2016 [31]. This study found that the administration of clove bud extract for 90 days at doses up to $1 \mathrm{~g} / \mathrm{kg}$ did not generate observable clinical signs of injury to the liver or kidneys in Wistar rats. Therefore, it is believed that the oral administration of clove oil may be safe at doses under $1 \mathrm{~g} / \mathrm{kg}$ in animal models.

\section{Conclusion}

Clove oil at a dose of $10 \mathrm{mg} / \mathrm{kg}$ reduced the nephrotoxicity of levofloxacin based on the serum levels of creatinine, urea, and the renal MDA analysis. In addition, clove oil at a dose of $10 \mathrm{mg} / \mathrm{kg}$ was also found to lessen renal histopathological injury, which was otherwise intense and diffused in the levofloxacin rats treated with placebo only. The protection provided by $10 \mathrm{mg} / \mathrm{kg}$ of clove oil and Curcuma extract was similar. Therefore, it is assumed that clove oil might potentially be used as a nephroprotective agent against kidney damage due to the chronic use of levofloxacin.

Limitations of the study: The clove oil nephroprotective effect is believed to occur due to its antioxidant properties. However, this study did not measure the levels of antioxidant enzymes at the end of the experiments to confirm a potential antioxidant-related mechanism for the nephroprotective effect of clove oil.

Recommendations for future research: We recommend that in further studies the levels of endogenous antioxidants be explore in animal models. To verify the nephroprotective effect of clove oil, potential enzymes to be investigated following clove oil treatment may include superoxide dismutase, glutathione peroxidase and catalase.

\section{Ethical Considerations}

\section{Compliance with ethical guidelines}

All experimental protocols involving animals have been granted institutional ethical clearance number of UH20050197 under Faculty of Medicine, Hasanuddin University.

\section{Funding}

The project was funded by the Ministry of Research, Technology, and Higher Education of Indonesia. 


\section{Authors' contributions}

Conceptualization and supervision: Yulia Djabir, Arif Santoso, Ismail Ismail; Methodology: Yulia Djabir, Ismail Ismail; Investigation and data collection: Anitsah Fiqardina, Syafira Salsabil; Writing - original draft: Anitsah Fiqardina; Writing - review \& editing: All authors; Funding acquisition and resources: Yulia Djabir, Arif Santoso.

\section{Conflict of interest}

The authors declared no conflict of interests with any entity in conducting this study.

\section{Acknowledgments}

The authors would like to thank Professor Subehan, Dr. Aliyah, and Professor Elly Wahyudin for their valuable suggestions to improve the quality of the research.

\section{References}

[1] Hooper DC, Jacoby GA. Topoisomerase inhibitors: Fluoroquinolone mechanisms of action and resistance. Cold Spring Harb Perspect Med. 2016; 6(9):a025320. [DOI:10.1101/cshperspect.a025320] [PMID] [PMCID]

[2] Nagaraja V, Godbole AA, Henderson SR, Maxwell A. DNA topoisomerase I and DNA gyrase as targets for tb therapy. Drug Discov Today. 2017; 22(3):510-8. [DOI:10.1016/j. drudis.2016.11.006] [PMID]

[3] Mirzayev F, Viney K, Linh NN, Gonzalez-Angulo L, Gegia M, Jaramillo E, et al. World Health Organization recommendations on the treatment of drug-resistant tuberculosis, 2020 update. Eur Respir J. 2020; 57(6):2003300. [DOI:10.1183/13993003.03300-2020] [PMID] [PMCID]

[4] Tesfahuneygn G, Medhin G, Legesse M. Adherence to antituberculosis treatment and treatment outcomes among tuberculosis patients in Alamata district, northeast Ethiopia. BMC Res Notes. 2015; 8:503. [DOI:10.1186/s13104-015-1452-x] [PMID] [PMCID]

[5] Orman ES, Conjeevaram HS, Vuppalanchi R, Freston JW, Rochon R, Kleiner DE, et al. Clinical and histopathologic features of fluoroquinolone-induced liver injury. Clin Gastroenterol Hepatol. 2011; 9(6):517-23. [DOI:10.1016/j. cgh.2011.02.019] [PMID] [PMCID]

[6] Bird ST, Etminan M, Brophy JM, Hartzema AG, Hartzema AG, Delaney JAC. Risk of acute kidney injury associated with the use of fluoroquinolones. CMAJ. 2013; 185(10):E475-82. [DOI:10.1503/cmaj.121730] [PMID] [PMCID]
[7] Buziashvili M, Mirtskhulava V, Kipiani M, Blumberg HM, Baliashvili D, Magee MJ, et al. Rates and risk factors for nephrotoxicity and ototoxicity among tuberculosis patients in Tbilisi, Georgia. Int J Tuberc Lung Dis. 2019; 23(9):1005-11. [DOI:10.5588/ijtld.18.0626] [PMID] [PMCID]

[8] Djabir YY, Arsyad A, Murdifin M, Tayeb R, Nur Amir M, Al-Fia Kamaruddin F, et al. Kleinhovia hospita extract alleviates experimental hepatic and renal toxicities induced by a combination of antituberculosis. J Herbmed Pharmacol. 2021; 10(1):102-8. [DOI:10.34172/jhp.2021.10]

[9] Hussein O, Germoush M, Mahmoud A. Ruta graveolens protects against isoniazid/rifampicin-induced nephrotoxicity through modulation of oxidative stress and inflammation. Glob J Biotechnol Biomater Sci. 2016; 1(1):17-22. [DOI:10.17352/gjbbs.000005]

[10] Cortés-Rojas DF, de Souza CRF, Oliveira WP. Clove (syzygium aromaticum): A precious spice. Asian Pac J Trop Biomed. 2014; 4(2):90-6. [DOI:10.1016/S2221-1691(14)60215-X] [PMID] [PMCID]

[11] El-Mesallamy AM, El-Gerby M, Azim MHAE. Antioxidant, antimicrobial activities and volatile constituents of clove flower buds oil. J Essent Oil Bearing Plants. 2012; 15(6):900-7. [DOI:10.1080/0972060X.2012.10662592]

[12] Sohilait H, Kainama H, and Nindatu M. Chemical composition and antibacterial activity of the essential oils from different parts of Eugenia caryophylata, Thunb grown in Amboina Island. Int J Organ Chem. 2018; 8(2):229-39. [DOI:10.4236/ ijoc.2018.82017]

[13] Selles SMA, Kouidri M, Belhamiti BT, Amrane AA. Chemical composition, in-vitro antibacterial and antioxidant activities of syzygium aromaticum essential oil. J Food Measure Charact. 2020; 14(4):2352-8. [DOI:10.1007/s11694-020-004825] [PMCID]

[14] Gülçin I, Elmastaş M, Aboul-Enein HY. Antioxidant activity of clove oil - a powerful antioxidant source. Arab J Chem. 2012; 5(4):489-99. [DOI:10.1016/j.arabjc.2010.09.016]

[15] Djabir YY, Sumarheni S, Aminullah A. Clove oil (Oleum caryophylli) effects on liver and renal function biomarkers in rats treated with toxic dose of isoniazid-rifampicin in. Paper presented at: The 4th International Conference of Science. 2020; Makassar, Indonesia. https://scholar.google.com/ scholar?hl=en\&as_sdt $=0 \% 2 \mathrm{C} 5 \& \mathrm{q}=+\mathrm{oil}+\% 28 \mathrm{Ol}+\& \mathrm{btnG}=$

[16] Humbal BR, Sadariya KA, Prajapati JA, et al. Safety evaluation of syzygium aromaticum oil in male and female wistar rats. J Pharmacogn Phytochem. 2019; 8(4):3027-32. https://www. phytojournal.com/archives?year $=2019 \& v o l=8 \&$ issue $=4 \&$ Art icleId $=9413$

[17] Nair AB, Jacob S. A simple practice guide for dose conversion between animals and human. J Basic Clin Pharm. 2016; 7(2):27-31. [DOI:10.4103/0976-0105.177703] [PMID] [PMCID]

[18] Kim SH, Hong KO, Hwang JK, et al. Xanthorrhizol has a potential to attenuate the high dose cisplatin-induced nephrotoxicity in mice. Food Chem Toxicol. 2005; 43(1):117-22. [DOI:10.1016/j.fct.2004.08.018] [PMID]

[19] Djabir Y, Adnan J, Amaliah N, et al. Roselle (Hibiscus sabdariffa L.) calyx water extract ameliorates isoniazid and rifampicin induced liver and renal injuries in rats. J Herbmed Pharmacol. 2021; 10(3):296-303. [DOI:10.34172/jhp.2021.34] 
[20] Talla V and Veerareddy PR. Oxidative stress induced by fluoroquinolones on treatment for complicated urinary tract infections in Indian patients. J Young Pharmacists. 2011; 3(4):304-9. [DOI:10.4103/0975-1483.90242] [PMID] [PMCID]

[21] El Ghallab Y, Al Jahid A, Eddine JJ, Haj Said AA, Zarayby L, Derfoufi S. syzygium aromaticum L.: Phytochemical investigation and comparison of the scavenging activity of essential oil, extracts and eugenol. Adv Tradit Med. 2020; 20(2):153-8. [DOI:10.1007/s13596-019-00416-7]

[22] Mohammadi Nejad S, Özgüneş H, Başaran N. Pharmacological and toxicological properties of eugenol. Turk J Pharm Sci. 2017; 14(2):201-6. [DOI:10.4274/tjps.62207] [PMID] [PMCID]

[23] Sharma UK, Kumar R, Gupta A, Ganguly R, Singh AK, Ojha AK, et al. Ameliorating efficacy of eugenol against metanil yellow induced toxicity in albino wistar rats. Food Chem Toxicol 2019; 126:34-40. [DOI:10.1016/j.fct.2019.01.032] [PMID]

[24] Ogata M, Hoshi M, Urano S, Endo T. Antioxidant activity of eugenol and related monomeric and dimeric compounds. Chem Pharm Bull (Tokyo). 2000; 48(10):1467-9. [DOI:10.1248/ cpb.48.1467] [PMID]

[25] Pandya D, Nagrajappa AK, Ravi KS. Assessment and correlation of urea and creatinine levels in saliva and serum of patients with chronic kidney disease, diabetes and hypertension- A research study. J Clinical and Diagnostic Res. 2016; 10(10):ZC58-62. [DOI:10.7860/JCDR/2016/20294.8651] [PMID] [PMCID]

[26] Hosten AO. Bun and creatinine. In: Walker HK, Hall WD, Hurst JW, editors. Clinical Methods: The History, Physical, and Laboratory Examinations. Oxford: Butterworths; 1990. [PMID]

[27] Djabir YY, Arsyad A, Usmar U, Wahyudin E, Arwi H, Rupang IS. The stages of development of liver and renal injuries in rats induced by fixed dose combination of antituberculosis regimen. FABAD J Pharm Sci. 2020; 45(1):29-35. http://dergi. fabad.org.tr/pdf/volum45/Issue1/29-35.pdf

[28] Liu Y. Renal fibrosis: New insights into the pathogenesis and therapeutics. Kidney Int. 2006; 69(2):213-7. [DOI:10.1038/ sj.ki.5000054] [PMID]

[29] Lomaestro B. Fluoroquinolone-induced renal failure. Drug Saf. 2000; 22(6):479-85. [DOI:10.2165/00002018-20002206000006] [PMID]

[30] Olayinka ET, Ore A, Ola OS. Influence of different doses of levofloxacin on antioxidant defense systems and markers of renal and hepatic dysfunctions in rats. Adv Toxicol. 2015; 2015:385023. [DOI:10.1155/2015/385023]

[31] Vijayasteltar L, Nair GG, Maliakel B, Kuttan R, Krishnakumar IM. Safety assessment of a standardized polyphenolic extract of clove buds: Subchronic toxicity and mutagenicity studies. Toxicol Rep. 2016; 3:439-49. [DOI:10.1016/j. toxrep.2016.04.001] [PMID] [PMCID] 